\title{
Compact Differential-Fed Planar Filtering Antennas
}

\author{
Emadeldeen Hassan ${ }^{1,2} * \mathbb{0}$, Denys Martynenko ${ }^{3}$, Eddie Wadbro ${ }^{1}$, Gunter Fischer ${ }^{3}$ \\ and Martin Berggren ${ }^{1}(D)$ \\ 1 Department of Computing Science, Umeå University, 90187 Umeå, Sweden; eddiew@cs.umu.se (E.W.); \\ martinb@cs.umu.se (M.B.) \\ 2 Department of Electronics and Electrical Communications, Menoufia University, 32952 Menouf, Egypt \\ 3 IHP_Leibniz-Institut für innovative Mikroelektronik, Im Technologiepark 25, \\ 15236 Frankfurt (Oder), Germany; martynenko@ihp-microelectronics.com (D.M.); \\ gfischer@ihp-microelectronics.com (G.F.) \\ * Correspondence: emad@cs.umu.se or emadtork@yahoo.com
}

Received: 27 September 2019; Accepted: 25 October 2019; Published: 30 October 2019

\begin{abstract}
This paper proposes novel low-profile differential-fed planar antennas with embedded sharp frequency selectively. The antennas are compact and easy to integrate with differential devices without matching baluns. The antenna design is formulated as a topology optimization problem, where requirements on impedance bandwidth, directivity, and filtering are used as the design objectives. The optimized antennas operate over the frequency band $6.0-8.5 \mathrm{GHz}$. The antennas have reflection coefficients below $-15 \mathrm{~dB}$, cross-polarization levels below $-42 \mathrm{~dB}$, a maximum gain of $6.0 \pm 0.5 \mathrm{~dB}$, and a uniform directivity over more than $130^{\circ}$ beamwidth angle in the frequency band of interest. In addition, the antennas exhibit sharp roll-off between the operational band and frequencies around the $5.8 \mathrm{GHz}$ WiFi band and the $10 \mathrm{GHz}$ X-band. One antenna has been fabricated with a good match between simulation and measurement results.
\end{abstract}

Keywords: antennas; differential line; planar circuits; filters; directivity; topology optimization; wideband systems

\section{Introduction}

Wireless communication and sensing systems are continuously raising new demands not only on performance of components, but also on their miniaturization, integration with on-chip devices, environmental effects, and costs. Planar components are easy to fabricate, result in low-profile circuits, and are therefore cost-efficient [1-4]. The current design of planar circuits still, however, follows a conventional approach that relies on assemblage of basic building blocks, such as filters, hybrid couplers, and antennas. The design of each component is accomplished in a separate design step and typically relies on simple structures inspired from circuit and transmission line theories. Although this design methodology is beneficial for design reuse, it results in large circuit footprints and high insertion losses.

Filtering antennas are components designed to offer antennas with specified filtering responses to decrease interference with surrounding wireless systems [5-9]. The design of filtering antennas is currently accomplished by following one of two approaches. The first is to use a separate filtering structure that precedes the antenna [10]. This approach has the drawback of increasing both the insertion loss and the footprint of the whole circuit. The second approach uses parasitic elements inside/near the antenna structure $[5,6,9]$. This approach is suitable for narrow band antennas, such as microstrip antennas; however, it typically requires a redesign of the antenna to account for the presence of the parasitic objects. Moreover, this latter strategy is typically time-consuming and may result in structures that are complex to fabricate [5,11]. In a recent work, Liu et al. [6] proposed to 
suppress the out-of-band radiation of a filtering patch antenna by using dissipative resistors. The use of dissipative resistors has the advantage of decreasing the energy reflected back to the amplifier. However, the dissipated energy increases the risk of heating up the circuit.

In the literature, most of the previously published filtering antennas rely on structures inspired from circuit and transmission line theories. Following a different approach, this work uses topology optimization techniques to design planar differential-fed filtering antennas. Topology optimization techniques, initially proposed for structural optimization [12,13], have been employed to design various electromagnetic components, such as antennas, filters, and waveguide transitions [14-18]. In topology optimization, each pixel (2D) or voxel (3D) inside the design domain is subject to design. Hence, topology optimization techniques are sometimes referred to as being parameter-free methods. Typically, these optimization techniques rely on sensitivity analysis and gradient-based optimization methods to seek designs (shapes) that satisfy the design objectives. Because of the vast degrees of freedom handled by these algorithms, they can reveal new conceptual designs. Moreover, recent designs obtained by these techniques have proven their ability not only to offer novel devices, but also to provide designs that satisfy manufacturing constraints [18].

The main interest of the current work is to optimize the antenna of a positioning system that operates over the frequency band $6.0-8.5 \mathrm{GHz}$. One essential operational requirement for such system is to possess a stable coverage over a wide beamwidth. Moreover, this positioning system is intended for use in sites where other wireless communication systems operating at the $5.8 \mathrm{GHz}$ WiFi frequency band could be sources of mutual interference. Therefore, we propose to design differential-fed planar antennas that combine requirements on a wide impedance bandwidth, a stable directivity, and a filtering of the out-of-band frequencies. We aim to exploit the vast degrees of freedom offered by topology optimization to design such antennas. We formulate the problem of the antenna design as a mathematical topology optimization problem, in which all design requirements are embedded a priori as objective functions or constraints. That is, using a very large space of feasible designs, the algorithm seeks structures that accomplish multiple objectives. Using manual design procedures, it can be very difficult to manage a large design space and multiple objectives. The choice of differential lines to feed the antennas makes them suitable for use with differential RF amplifiers [1]. Moreover, this type of feeding typically results in very low cross-polarization levels $[19,20]$.

\section{Problem Formulation and Numerical Treatment}

Figure 1 illustrates the conceptual setup. The design area of the antenna is the domain $\Omega=\Omega_{1} \cup \Omega_{2}$, where both $\Omega_{1}$ and $\Omega_{2}$ have an area $h \times l$. A differential strip line, printed on a dielectric substrate, feeds the antenna region. The differential line has a line impedance $Z_{c p}$ which can be estimated based on the strip width $w$, the strip separation distance $s$, and the permittivity of the supporting substrate [21]. The other side of the differential line is attached to a voltage source with an internal impedance $Z_{s}$. Here, we assume that the source and the differential line are matched and both $Z_{c p}$ and $Z_{s}$ are real. The problem setup entails a mirror symmetry of the model in the $x z$ plane. We exploit this symmetry and halve the analysis domain by placing an electric wall at the plane of symmetry. To preserve the matching to the differential line, the source impedance is consequently halved to $0.5 Z_{s}$ [22]. We remark that Figure 1 represents a generic differential-feed setup that can be used to model various conventional antenna geometries, such as dipole antennas, travelling wave antennas, and microstrip antennas.

Here, the design objectives are (i) the minimization of the antenna reflection coefficient over the band $6.0-8.5 \mathrm{GHz}$, (ii) the maximization of the antenna radiation in the positive $z$ half-space, and (iii) the minimization of the antenna realized gain outside the band of interest. We include the first objective to the optimization problem formulation as the minimization of the energy reflected by the antenna in its transmission mode. The second objective is formulated based on the antenna receiving mode. We include the maximization of the received signals from a set of external plane waves propagating toward the antenna in the $-z,+x$, and $-x$ directions. This design objective is 
equivalent to increasing the antenna aperture area over the frequency band of interest and accounting for the specified directivity [22]. We address the third design objective by maximizing the reflection coefficient of the antenna over neighboring frequencies. For this purpose, we include two additional terms to the objective function to maximize the reflection coefficient at the lower and upper frequencies. We remark that the latter objective results in the minimization of the realized (absolute) gain of the antenna outside the frequency band of interest.

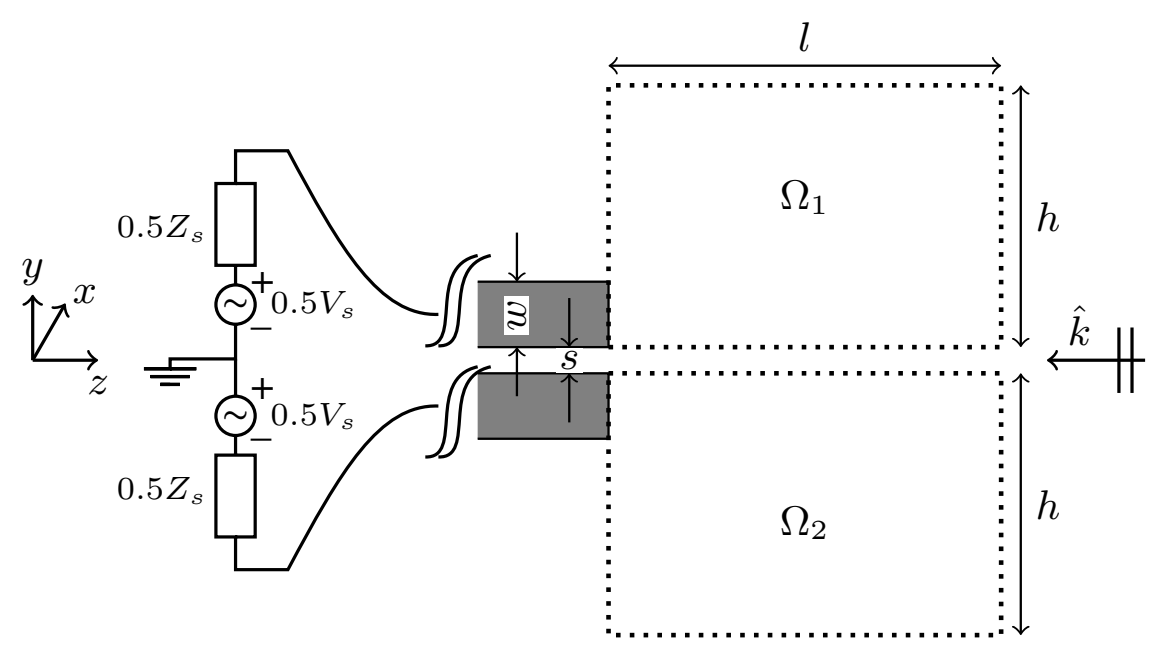

Figure 1. The design domain $\Omega=\Omega_{1} \cup \Omega_{2}$ is connected to a source $V_{s}$, with an internal impedance $Z_{S}$, through a differential-fed strip line at the center of the left side. Each of the domains $\Omega_{1}$ and $\Omega_{2}$ has an area $h \times l$ where a metallic material (copper) is to be distributed to achieve the design objectives.

In the transmitting mode, we use the source to excite the antenna with three different signals that impose the energy $\boldsymbol{W}_{\mathrm{in}, \mathrm{i}}, \boldsymbol{W}_{\mathrm{in}, 1}$, and $\boldsymbol{W}_{\mathrm{in}, \mathrm{u}}$. The last index refers to the frequency contents of the excitation signal. That is, $i, 1$, and $u$ refer, respectively, to the in-band frequencies, the lower-band frequencies, and the upper-band frequencies. For each excitation, we observe the corresponding outgoing energy, $\boldsymbol{W}_{\text {out, },}, \boldsymbol{W}_{\text {out, }, 1}$ and $\boldsymbol{W}_{\text {out,u }}$, at the differential line end. In the receiving mode, we excite the model problem by three plane waves propagating in the $-z,-x$, and $+x$-directions with the electric field linearly polarized in the $y$-direction [14,23], and we observe the outgoing energy $\boldsymbol{W}_{\text {out,p }}$ at the differential line end. Based on the aforementioned discussion, we formulate the optimization problem

$$
\begin{array}{cc}
\min _{\sigma_{\Omega}} & \log \left(\frac{\boldsymbol{W}_{\text {out, } \mathrm{i}}}{\boldsymbol{W}_{\text {out }, 1} \boldsymbol{W}_{\text {out }, \mathrm{p}} \boldsymbol{W}_{\text {out }, \mathrm{u}}}\right), \\
\text { subject to } & \text { the governing equations, } \\
& \text { the imposed excitations. }
\end{array}
$$

Note that problem (1) implies the maximization of the factors in the denominator. Problem (1) reads: seek the distribution of the conductivity values $\sigma$ in the design domain $\Omega=\Omega_{1} \cup \Omega_{2}$, enclosed by the dotted lines in Figure 1, to satisfy the multi-objective function and the constraints.

To compute the factors in problem (1), we use numerical solutions to Maxwell's equations by the finite-difference time-domain (FDTD) method [24]. A coaxial waveguide port, with line impedance $0.5 Z_{s}$ and attached to the differential line end, models the source. We extend the one cell model, previously published by Hassan et al. [14], to include a square inner probe with size $w$ (as the strip line width). The reflection coefficient between the coaxial waveguide port and the strip line is below $-25 \mathrm{~dB}$ over the frequency band of interest. The plane waves excitations are imposed by using the total-field scattered-field formulation [24]. 
To solve optimization problem (1), we rely on the so-called density-based topology optimization approach. The values of the conductivities at each Yee edge (pixel) in the design domain $\Omega$ are subject to design. We allow the design variables to vary continuously between two extreme values that indicate presence or absence of material. Here, these extreme values are the conductivities of a good conductor and a good dielectric. Based on numerical investigations, we consider materials with conductivity $\sigma=10^{5} \mathrm{~S} / \mathrm{m}$ and $\sigma=10^{-3} \mathrm{~S} / \mathrm{m}$ as a good conductor and a good dielectric, respectively $[18,25]$. The vector of pixelated conductivities is mapped to a design vector $\mathbf{p}$ with entries varying between 0 and 1 . Here, the values 0 and 1 represent a good dielectric and a good conductor, respectively. Although the entries of vector $\mathbf{p}$ may hold any value between 0 and 1 during the optimization, the final entries must hold either 0 or 1 to allow the fabrication of the design. Allowing the design variables to vary continuously makes it possible to devise adjoint field systems and compute the gradient information of the factors in problem (1) in an efficient way [14,26]. After computing the factors in problem (1) and their gradient information, we employ Svanberg's GCMMA algorithm [27] to iteratively solve problem (1). Detailed description of the discretization and the numerical treatment can be found in previous work $[14,18,28]$.

\section{Results}

In the FDTD method, we use a spatial discretization step $\Delta$ of $0.0625 \mathrm{~mm}$, a temporal discretization step $\Delta t$ that equals 0.95 of the Courant limit, and 15 cells of a uniaxial perfectly matched layer to simulate the radiation boundary condition. As mentioned in Section 2, we exploit the problem symmetry to halve the analysis domain. We use a design domain $\Omega_{1}$ of area $11.25 \times 13.5 \mathrm{~mm}^{2}$, discretized into $180 \times 216$ Yee faces, which yields 78156 unknown edge conductivities that correspond to the entries of design vector $\mathbf{p}$. To hold the copper distribution, the design domain is backed by a Rogers RO3003 substrate that has a thickness of $0.127 \mathrm{~mm}$, a relative permittivity of 3, and a loss tangent of 0.001 at $10 \mathrm{GHz}$. The employed differential line has $w=s=0.25 \mathrm{~mm}$. The frequency bands of interest are the in-band frequencies $6.0-8.5 \mathrm{GHz}$, the lower-band frequencies $3.5-6.0 \mathrm{GHz}$, and the upper-band frequencies $8.5-11.0 \mathrm{GHz}$. To cover these frequency bands, we use time-domain sinc signals that are truncated after 6 lobes. Each sinc signal is used to modulate a frequency carrier at the mid of the corresponding frequency interval. We implement the FDTD method to run on graphics processing units (GPUs), and we use uniform FDTD cubical grids in all simulations. We run the numerical experiments on compute nodes equipped with Nvidia V100 GPU cards and with 128 GB internal memory. Based on the current problem discretization, one call to the FDTD solver takes $150 \mathrm{~s}$. We remark that the evaluation of each factor in problem (1) requires one FDTD simulation, and the evaluation of the corresponding gradient requires one additional FDTD simulation.

First, we solve problem (1) without including the two filtering factors $\boldsymbol{W}_{\text {out,l }}$ and $\boldsymbol{W}_{\text {out,u }}$. That is, the antenna is optimized only for the minimization of the reflected energy $W_{\text {out,i }}$ and the maximization of the received energy $\boldsymbol{W}_{\text {out,p }}$ from the specified directions. Figure 2 shows some snapshots illustrating the development of the design during the optimization. We use a uniform initial distribution of the design variables that corresponds to a conductivity of $140 \mathrm{~S} / \mathrm{m}$ at each Yee edge in the design domain. To secure a connection path between the design domain and the strip line, a square region of area $2 w \times 2 w \mathrm{~mm}^{2}$ is fixed to be copper at the lower left corner of the design domain. The antenna layout evolves in 136 iterations from a design with large amount of grayness and fuzzy boundaries to a final design with black and white materials as well as crisp boundaries. We stress that each pixel in this design (image) is a design variable, and that such large-scale optimization problem is computationally prohibitive to solve by stochastic optimization techniques, such as genetic algorithms $[29,30]$. 


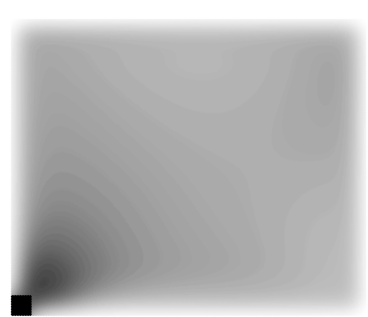

Iter.\# 1

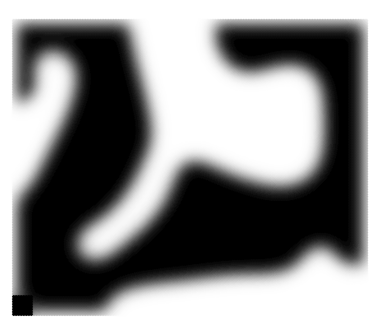

Iter.\# 34

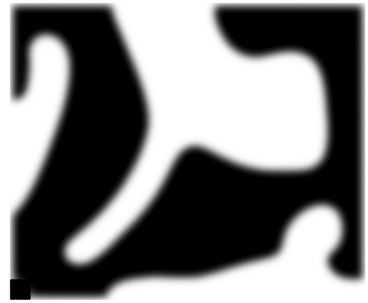

Iter.\# 68

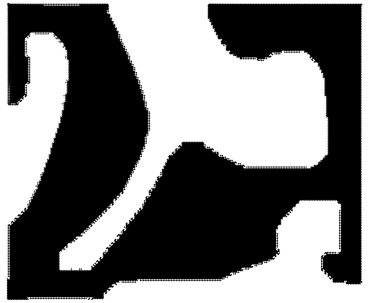

Iter.\# 136

Figure 2. Development of the physical design of the reference antenna over iterations 1, 34, 68, and 136.

Black color indicates a good conductor and white color indicates a good dielectric.

Figure 3a shows the structure of the optimized antenna. The antenna consists of two vertical branches with small cap extensions and a horizontally tapered section inbetween. Figure $3 b$ shows that the antenna has a reflection coefficient $\left|S_{11}\right|$ below $-10 \mathrm{~dB}$ over the frequency band of interest, marked by the vertical dashed lines. The cross-verification of $\left|S_{11}\right|$ shows a good agreement between our FDTD simulation results and the results obtained by the CST commercial package. The antenna has a small reflection coefficient also at frequencies outside the band of interest. More precisely, the antenna reflection coefficient is $-13.6 \mathrm{~dB}$ and $-5 \mathrm{~dB}$ at the WiFi frequency $5.8 \mathrm{GHz}$ and at $10 \mathrm{GHz}$, respectively. We emphasize that the use of a sinc signal in the excitation of the problem allows targeting the frequency band of interest. However, this choice of excitation does not imply any requirements on the out-of-band frequencies. We use this antenna as a reference to compare with the results presented below.

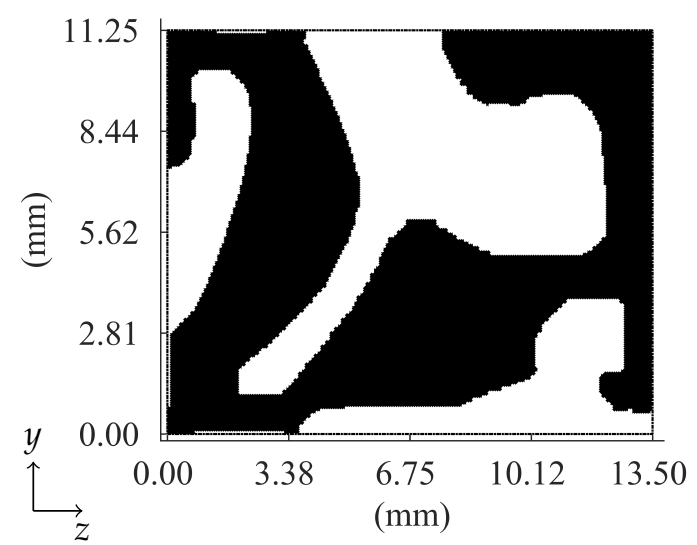

(a)

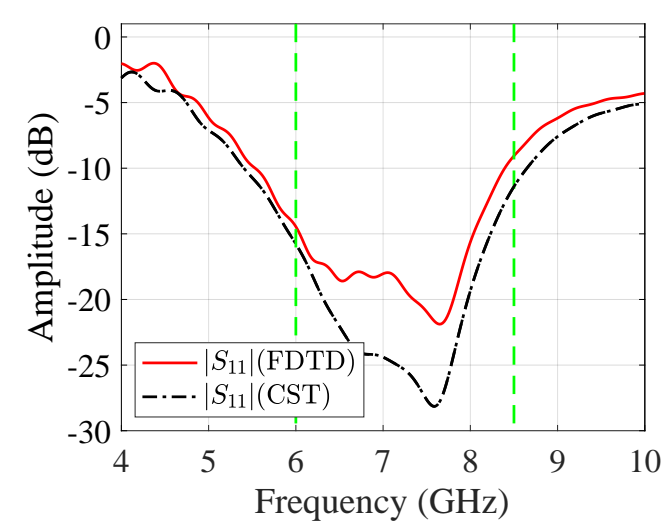

(b)

Figure 3. Reference antenna: (a) The shape of the antenna optimized to radiate over the frequency band 6.0-8.5 GHz. (b) Reflection coefficient of the antenna. The operational band is marked by the green dashed lines.

Figure $4 \mathrm{a}, \mathrm{b}$ show polar plots of the antenna realized gains in the $x z$ plane and $y z$ plane, respectively. The antenna radiation pattern is slightly narrower in the $y z$ plane compared to the $x z$ plane. In the two main planes, the cross-polarization level is less than $45 \mathrm{~dB}$, which is a typical feature of differential-fed antennas $[5,20]$. Table 1 summarizes the spatial radiation characteristics of the optimized antenna. The antenna has a maximum gain of $5 \pm 0.5 \mathrm{~dB}$ within the frequency band of interest, and the gain decreases to $3.4 \mathrm{~dB}$ and $2.1 \mathrm{~dB}$ at $5.5 \mathrm{GHz}$ and $9.5 \mathrm{GHz}$, respectively. In the $x z$ plane, the $3 \mathrm{~dB}$ beamwidth decreases as the frequency increases with a smallest value of $124^{\circ}$ in the frequency band of interest. In the $y z$ plane, the $3 \mathrm{~dB}$ beamwidth is essentially stable around $88^{\circ} \pm 2^{\circ}$ over the frequency band 6.5-8.5 GHz. Note that in the $x z$ plane, as the frequency increases, the antenna pattern forms a radiation dip, which can be clearly seen in the $-z$ direction at $7.5 \mathrm{GHz}$. The angle of this dip moves towards the 
$x$ direction $\left(\theta= \pm 90^{\circ}\right)$ as the frequency increases. Note that the pattern is more directive towards the $+z$ half-space, the direction from which the plane wave excitation impinges.

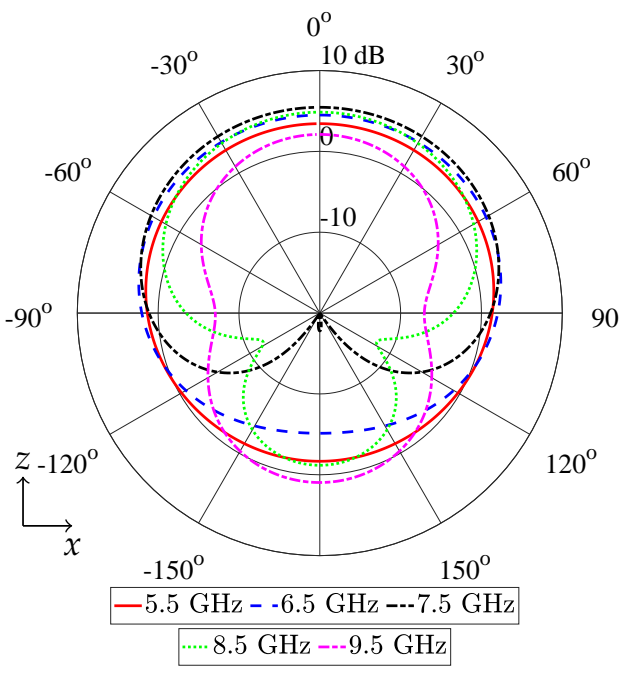

(a)

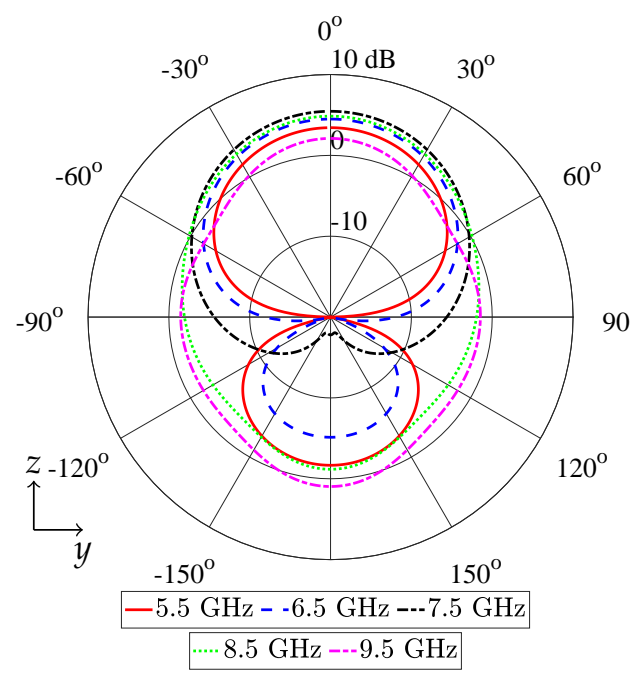

(b)

Figure 4. Reference antenna: (a) Realized gain in the $x z$ plane $(\phi=0)$. (b) Realized gain in the $y z$ plane $(\phi=90)$. The maximum cross-polarization level, not plotted here for brevity, is less than $57 \mathrm{~dB}$ and $45 \mathrm{~dB}$ for $\phi=0$ and $\phi=90$, respectively.

Table 1. Gain and beamwidth of the reference antenna (Figure 3).

\begin{tabular}{lccccc}
\hline Frequency (GHz) & $\mathbf{5 . 5}$ & $\mathbf{6 . 5}$ & $\mathbf{7 . 5}$ & $\mathbf{8 . 5}$ & $\mathbf{9 . 5}$ \\
\hline Gain $(\mathrm{dB})$ & 3.4 & 4.5 & 5.5 & 4.8 & 2.1 \\
Front-to-back ratio $(\mathrm{dB})$ & 5.1 & 9.6 & 23.3 & 6 & 1.2 \\
3 dB beamwidth $(x z$ plane) & $216^{\circ}$ & $194^{\circ}$ & $160^{\circ}$ & $124^{\circ}$ & $95^{\circ}$ \\
3 dB beamwidth (yz plane) & $82^{\circ}$ & $86^{\circ}$ & $86^{\circ}$ & $90^{\circ}$ & $84^{\circ}$ \\
\hline
\end{tabular}

The amplitude of the surface current and its direction determine the overall antenna gain [22]. To understand the working principle of the optimized antenna, we plot the surface current on the antenna at five frequencies, as shown in Figure 5. Figure 5a,e show that the current has different directions on the two vertical branches at $5.5 \mathrm{GHz}$ and $9.5 \mathrm{GHz}$. In Figure $5 \mathrm{~b}, \mathrm{c}$, the surface currents on the two vertical branches have essentially similar amplitudes and directions, which could explain the high gain at $6.5 \mathrm{GHz}$ and $7.5 \mathrm{GHz}$. Figure $5 \mathrm{~d}$ shows that the current has opposite directions on the two branches; however, the peak of the surface current is slightly drifted out towards the external branch. The change of the current directions results in the unexpected decrease of the antenna gain at $8.5 \mathrm{GHz}$.

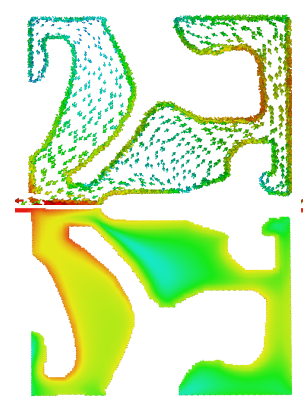

(a) $5.5 \mathrm{GHz}$

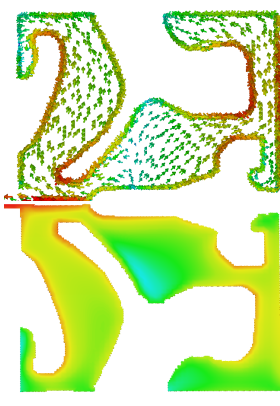

(b) $6.5 \mathrm{GHz}$

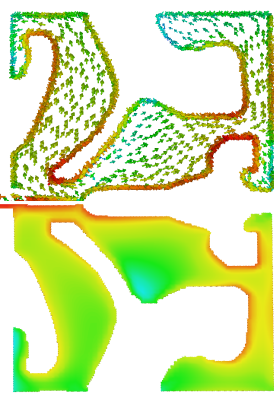

(c) $7.5 \mathrm{GHz}$

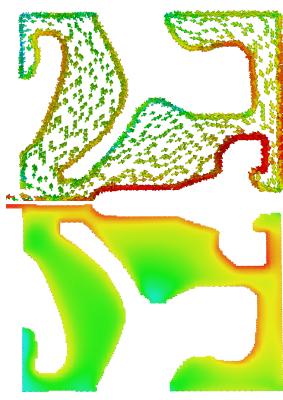

(d) $8.5 \mathrm{GHz}$

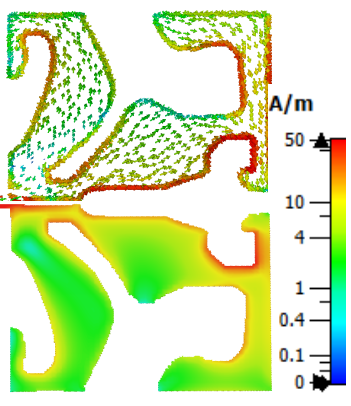

(e) $9.5 \mathrm{GHz}$

Figure 5. Surface current distribution on the reference antenna. 
Now we solve problem (1) with all factors of the design objectives included. The snapshots in Figure 6 show the development of the design during the optimization. Similar to Figure 2, we start the optimization with a uniform initial distribution. By comparing the two figures, one can see similar trend on the amount of grayness and development of the crisp boundaries. In addition, in both cases, the main layout of the design evolves in the early iterations, and more than $75 \%$ of the iterations are used to smoothly remove the grayness in the design and to shape the antenna's boundaries.

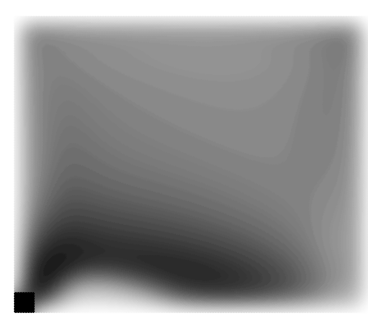

Iter.\# 1

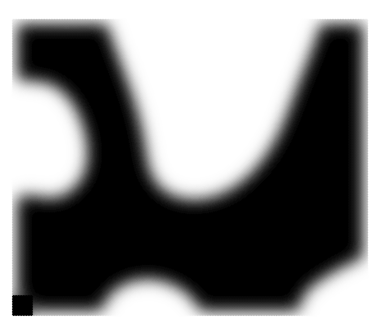

Iter.\# 34

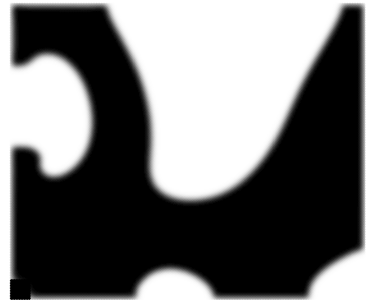

Iter.\# 68

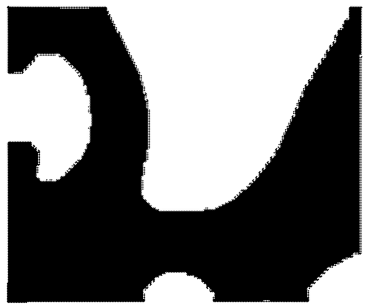

Iter.\# 129

Figure 6. Development of the physical design of Antenna II over iterations 1, 34, 68, and 129. Black color indicates a good conductor and white color indicates a good dielectric.

Figure 7a depicts the optimized antenna, denoted Antenna II. The structure consists of two vertical branches with partially tapered boundaries. The two branches are connected by a horizontal strip. The branch near the feeding line has a mushroom-like hollow area. Moreover, a hollow elliptical area is formed beneath the horizontal strip. Figure $7 \mathrm{~b}$ shows a manufactured prototype. For measurement purposes, the antenna is connected to a micrsotrip-to-differential line adapter and two SMA connectors, as shown in the figure. We use a ZVA24 Rohde\&Schwarz vector network analyzer to measure the antenna reflection coefficient. Figure $7 \mathrm{c}$ shows the antenna reflection coefficient. There is a reasonable match between the measured and simulated results. The antenna has a reflection coefficient around $-15 \mathrm{~dB}$ over the frequency band 6.2-8.2 GHz. Moreover, the antenna shows a sharp roll-off around $6 \mathrm{GHz}$. In particular, the antenna has a reflection coefficient of $-3.5 \mathrm{~dB}$ at the WiFi frequency $5.8 \mathrm{GHz}$ and $-2.5 \mathrm{~dB}$ at the $\mathrm{X}$-band frequency $10 \mathrm{GHz}$. Compared to the reference design, this antenna has sharper roll-off at the lower and upper-band edges. However, the band edge at the higher frequencies has a relatively moderate roll-off compared to the lower-band edge. We investigate this issue further below.

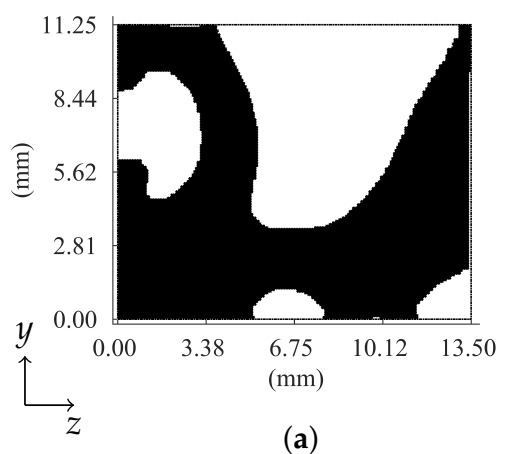

(a)

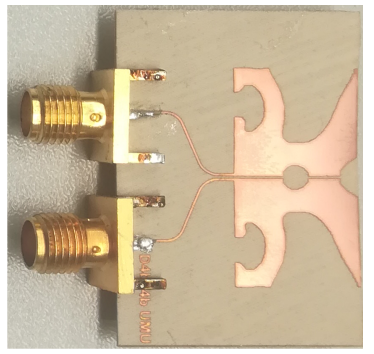

(b)

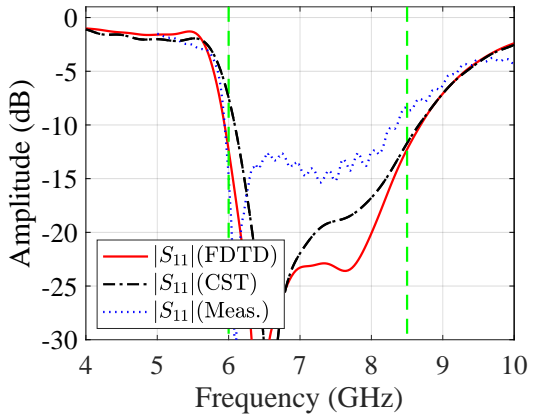

(c)

Figure 7. Antenna II: (a) The shape of the antenna optimized to radiate over the frequency band 6.0-8.5 GHz and to filter the frequencies 3.5-6.0 GHz and 8.5-11.0 GHz. (b) Photo of a manufactured prototype. (c) The measured and computed antenna reflection coefficient. The operational band is marked by the green dashed lines. 
Figure 8 shows the realized gain of the optimized antenna at five frequencies. Figure $8 \mathrm{a}, \mathrm{b}$ show the simulated and measured gain in the $x z$ plane, respectively. Similarly, Figure $8 \mathrm{c}, \mathrm{d}$, respectively, show the simulated and measured gain in the $y z$ plane. A photo of the setup for the antenna gain measurement is shown in Figure 8e. There is a good correlation between the simulated, Figure 8a,c, and the measured, Figure $8 \mathrm{~b}, \mathrm{~d}$, gain results. The small angular mismatch between the measured and simulated gain can be attributed to the adapter attached to the antenna during the measurements, which could also explain the slight difference, approximately $1 \mathrm{~dB}$, between the maximum amplitudes of the simulated and measured gain. Note the high suppression level of the antenna gain in the $+z$ direction to $-7.6 \mathrm{~dB}$ at $5.5 \mathrm{GHz}$. In the $x z$ and $y z$ planes and over the frequency band $6.5-8.5 \mathrm{GHz}$, the antenna has essentially a uniform angular gain distribution in the $+z$ half-space. The antenna has a maximum simulated gain of $6.15 \pm 0.55 \mathrm{~dB}$ in its operational band. The realized gain in the $+z$ direction still, however, has a high value of $5.1 \mathrm{~dB}$ at $9.5 \mathrm{GHz}$. The antenna has a $3 \mathrm{~dB}$ gain beamwidth above $136^{\circ}$ in the $x z$ plane, and a stable one, around $64^{\circ}$, in the $y z$ plane. The antenna gain characteristics are summarized in Table 2 .

Table 2. Maximum gain and $3 \mathrm{~dB}$ beamwidths of Antenna II (Figure 7).

\begin{tabular}{lccccc}
\hline Frequency (GHz) & $\mathbf{5 . 5}$ & $\mathbf{6 . 5}$ & $\mathbf{7 . 5}$ & $\mathbf{8 . 5}$ & $\mathbf{9 . 5}$ \\
\hline Gain $(\mathrm{dB})$ & -7.6 & 5.6 & 6.3 & 6.7 & 5.1 \\
Front-to-back ratio $(\mathrm{dB})$ & -4.3 & 18.9 & 22.6 & 10.8 & 6.8 \\
$3 \mathrm{~dB}$ beamwidth $(x z$ plane $)$ & $168^{\circ}$ & $158^{\circ}$ & $154^{\circ}$ & $136^{\circ}$ & $122^{\circ}$ \\
$3 \mathrm{~dB}$ beamwidth $(y z$ plane $)$ & $106^{\circ}$ & $62^{\circ}$ & $66^{\circ}$ & $64^{\circ}$ & $62^{\circ}$ \\
\hline
\end{tabular}

Figure 9 shows the surface current on Antenna II at five frequencies. At $5.5 \mathrm{GHz}$, the current has its peak at the horizontal strip, around the elliptical hollow slot between the antenna arms, as shown in Figure 9a. The current amplitude on the vertical branches is relatively small at this frequency, which is why the antenna absolute gain is small. At $7.5 \mathrm{GHz}$, the current has similar amplitudes and directions on the two branches, as shown in Figure 9c. At $6.5 \mathrm{GHz}$ and $8.5 \mathrm{GHz}$, the currents on the vertical branches have opposite directions; however, the current amplitude is higher on the right and the left branches, as shown in Figure 9b,d, respectively. The net radiation from the antenna is dominated by the branch with the higher current amplitude. Similar to the $6.5 \mathrm{GHz}$ and $8.5 \mathrm{GHz}$ frequencies, the current at $9.5 \mathrm{GHz}$ has different directions on the vertical branches and its peak appears on the left vertical branch, as shown in Figure 9e.

We attempt to further improve the antenna suppression level at the higher frequencies. To do so, we assign a weighting coefficient to prioritize the factor $\boldsymbol{W}_{\text {out,u }}$ over the other factors in problem (1). Figure 10 shows one additional design, Antenna III, and its reflection coefficient. In this design, we doubled the weighting of $W_{\text {out,u }}$ compared to the previous case. The shape and the performance of the new antenna share many similarities with the previous design. One can see the two vertical branches, the horizontal strip, as well as the slot between the two arms of the antenna. The antenna reflection coefficient has increased to $-2.4 \mathrm{~dB}$ and $-1.6 \mathrm{~dB}$ at $5.8 \mathrm{GHz}$ and $10 \mathrm{GHz}$, respectively. That is, around a $1 \mathrm{~dB}$ improvement compared to the previous design. In the meantime, the antenna still possesses a reflection coefficient below $-10 \mathrm{~dB}$ over the frequency interval $6.0-8.5 \mathrm{GHz}$. The antenna absolute gain, plotted in Figure 11 and summarized in Table 3, is $6.2 \pm 0.5 \mathrm{~dB}$ over the frequency band $6.5-8.5 \mathrm{GHz}$. The gain decreases to $-8.4 \mathrm{~dB}$ and $4.0 \mathrm{~dB}$ at $5.5 \mathrm{GHz}$ and $9.5 \mathrm{GHz}$, respectively. Figure 12 shows the current distribution on Antenna III, which has essentially the same characteristics as Antenna II. We remark that by increasing the weighting coefficient of the upper-band frequencies further, the optimization algorithm might down prioritize the other factors in problem (1). 


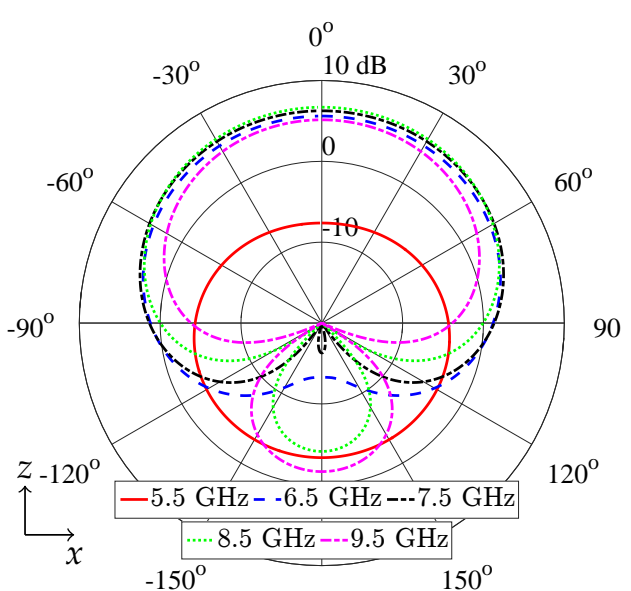

(a)

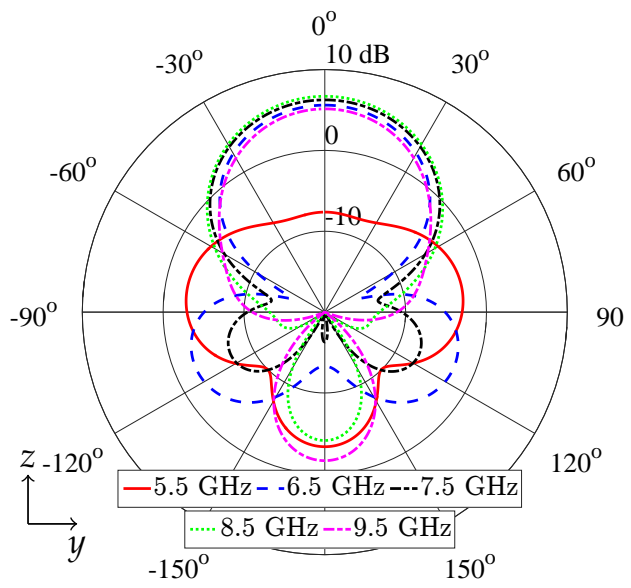

(c)

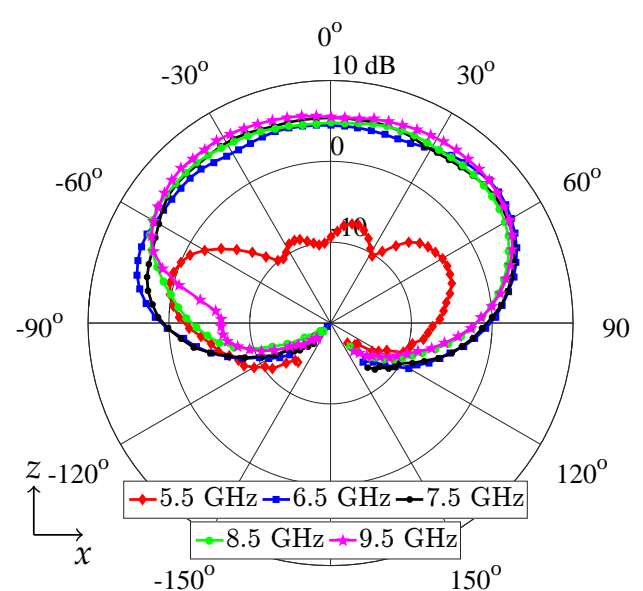

(b)

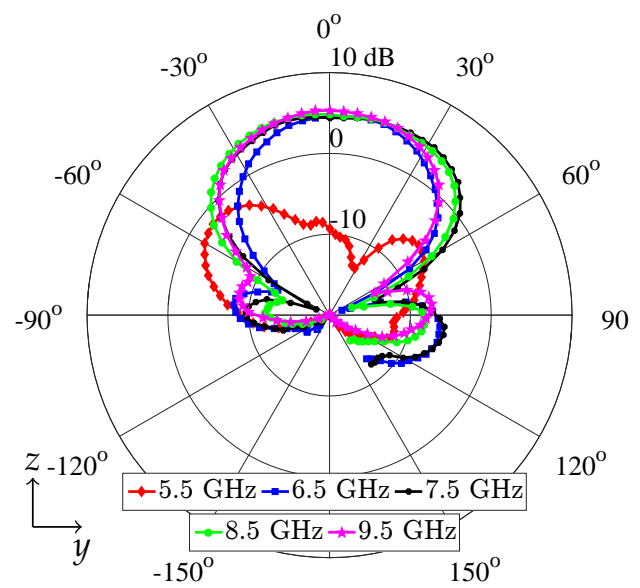

(d)

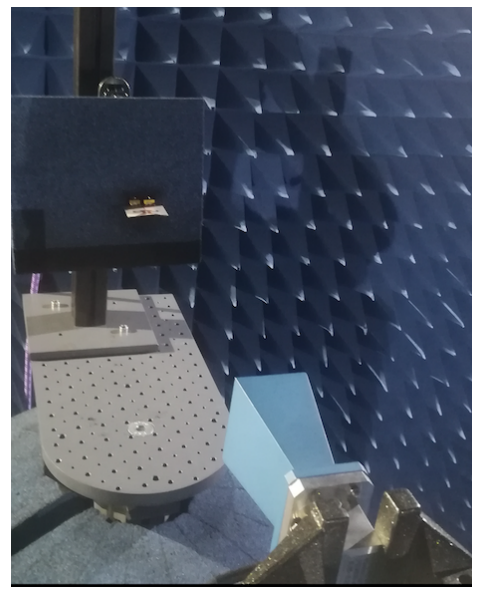

(e)

Figure 8. Antenna II: Simulated (a) and measured $(\mathbf{b})$ realized gain in the $x z$ plane $(\phi=0)$. Simulated (c) and measured (d) realized gain in the $y z$ plane $(\phi=90)$. The maximum simulated cross-polarization level, not plotted here for brevity, is less than $54 \mathrm{~dB}$ and $42 \mathrm{~dB}$ for $\phi=0$ and $\phi=90$, respectively. (e) Setup of the antenna gain measurements. 


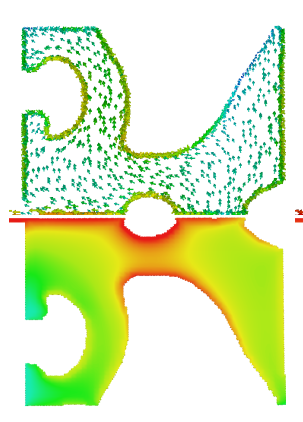

(a) $5.5 \mathrm{GHz}$

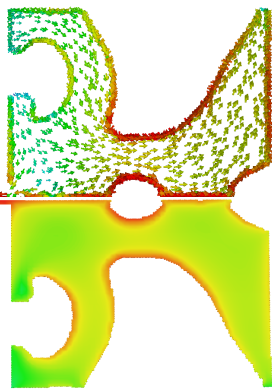

(b) $6.5 \mathrm{GHz}$

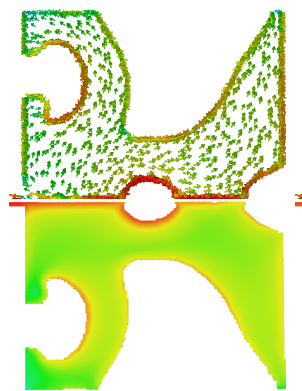

(c) $7.5 \mathrm{GHz}$

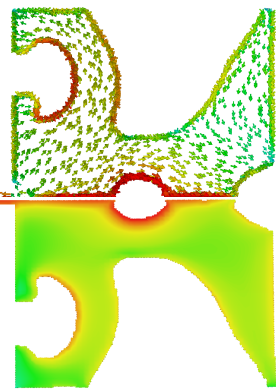

(d) $8.5 \mathrm{GHz}$

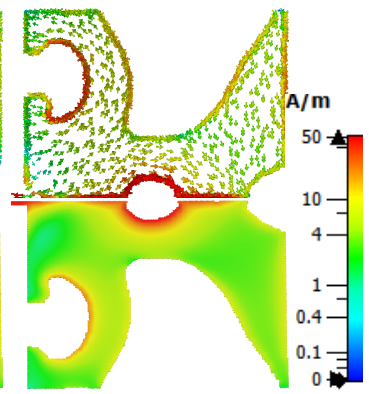

(e) $9.5 \mathrm{GHz}$

Figure 9. Surface current distribution on Antenna II.

Table 3. Maximum gain and $3 \mathrm{~dB}$ beamwidths of Antenna III (Figure 10).

\begin{tabular}{lccccc}
\hline Frequency (GHz) & $\mathbf{5 . 5}$ & $\mathbf{6 . 5}$ & $\mathbf{7 . 5}$ & $\mathbf{8 . 5}$ & $\mathbf{9 . 5}$ \\
\hline Gain $(\mathrm{dB})$ & -8.4 & 5.7 & 6.7 & 6.7 & 4.0 \\
Front-to-back ratio $(\mathrm{dB})$ & -3.2 & 18.1 & 14.2 & 7.3 & 4.4 \\
$3 \mathrm{~dB}$ beamwidth $(x z$ plane $)$ & $172^{\circ}$ & $150^{\circ}$ & $140^{\circ}$ & $122^{\circ}$ & $108^{\circ}$ \\
$3 \mathrm{~dB}$ beamwidth $(y z$ plane $)$ & $100^{\circ}$ & $60^{\circ}$ & $64^{\circ}$ & $62^{\circ}$ & $58^{\circ}$ \\
\hline
\end{tabular}

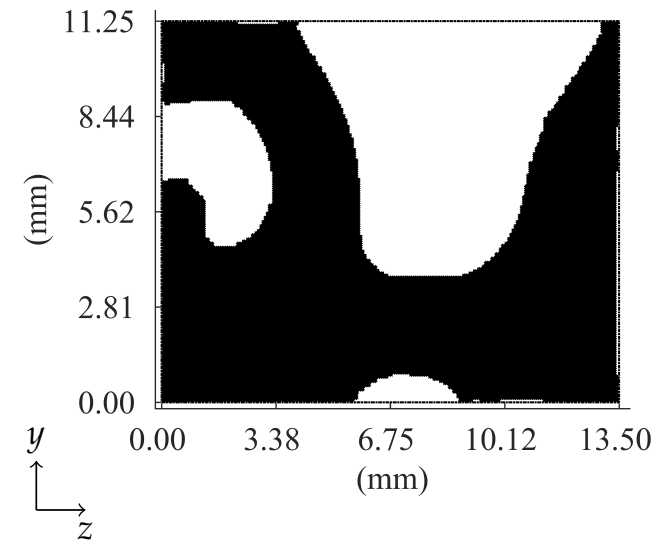

(a)

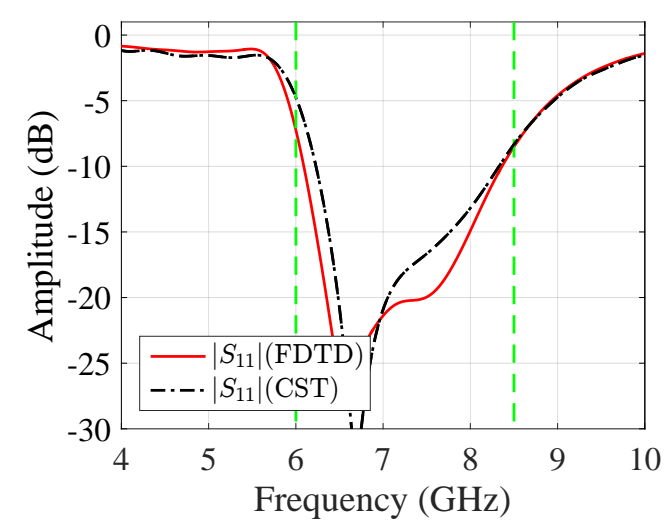

(b)

Figure 10. Antenna III: (a) The shape of the antenna optimized to radiate over the frequency band $6.0-8.5 \mathrm{GHz}$ and to filter the frequencies $3.5-6.0 \mathrm{GHz}$ and $8.5-11.0 \mathrm{GHz}$. (b) The antenna reflection coefficient. The operational band is marked by the green dashed lines.

Finally, we pursue a numerical experiment to investigate the impact of the design domain area on the solution of problem (1). We reduce the design domain area from $11.25 \times 13.5 \mathrm{~mm}^{2}$ to $10 \times 10 \mathrm{~mm}^{2}$ (34\% reduction in area) and solve problem (1) with the same settings as the previous case. In this case, the discretization of the design domain results in 51200 design variables. Figure 13 shows the structure of the optimized antenna, Antenna IV, and its reflection coefficient. The antenna structure has one vertical metallic branch, with a tapered outer boundary and a small cap, and the unfilled slot between the two arms still appears. The antenna reflection coefficient is below $-10 \mathrm{~dB}$ over the frequency interval $6.0-8.3 \mathrm{GHz},-8.1$ at $5.8 \mathrm{GHz}$, and -2.0 at $10.0 \mathrm{GHz}$. Compared to the previous designs, this antenna shows a sharper roll-off at the high band edge. The reduction in the available design space, however, makes it difficult to achieve sharp roll-off at the lower frequencies. 


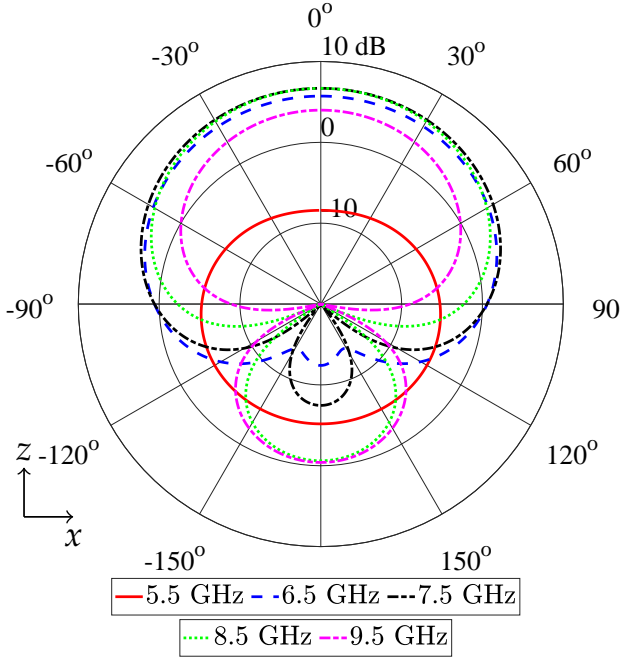

(a)

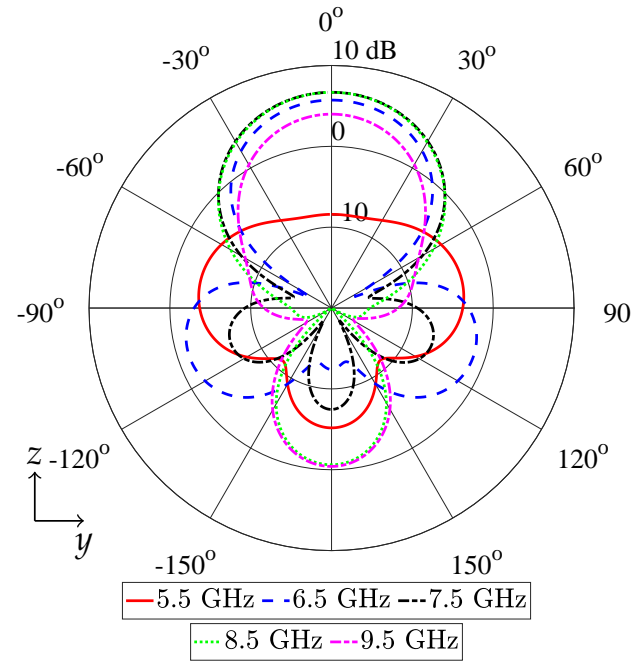

(b)

Figure 11. Antenna III (a) Realized gain in the $x z$ plane $(\phi=0)$. (b) Realized gain in the $y z$ plane $(\phi=90)$. The maximum cross-polarization level is less than $49 \mathrm{~dB}$ and $41 \mathrm{~dB}$ for $\phi=0$ and $\phi=90$, respectively.

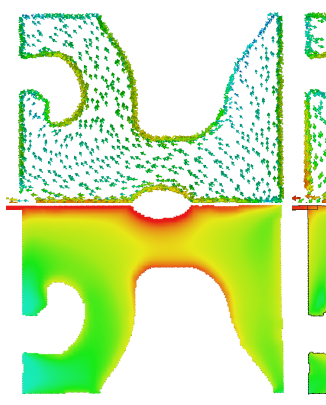

(a) $5.5 \mathrm{GHz}$

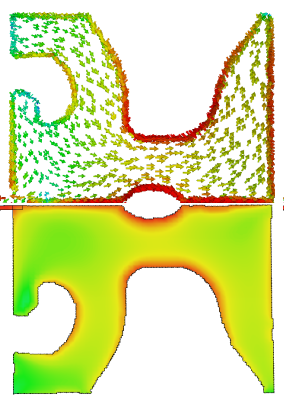

(b) $6.5 \mathrm{GHz}$

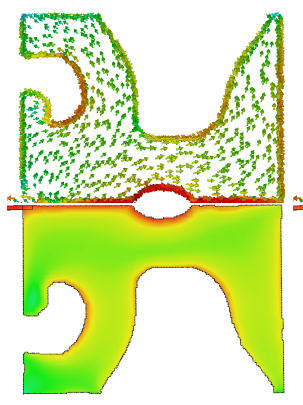

(c) $7.5 \mathrm{GHz}$

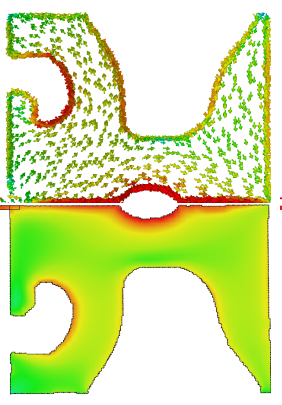

(d) $8.5 \mathrm{GHz}$

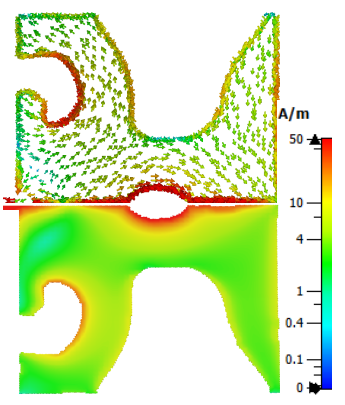

(e) $9.5 \mathrm{GHz}$

Figure 12. Surface current distribution on Antenna III.

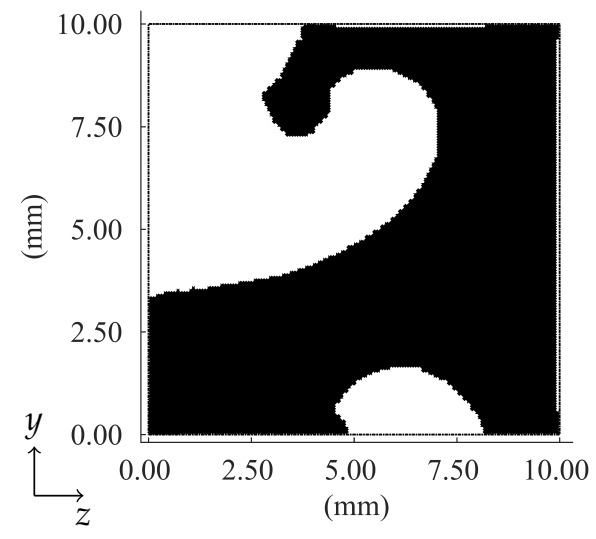

(a)

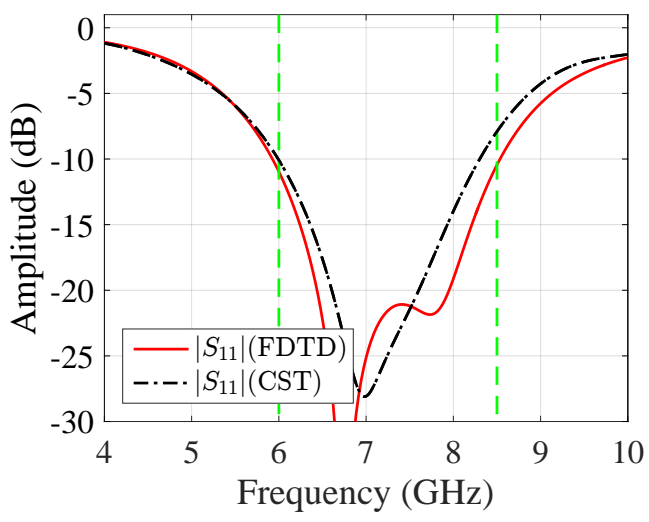

(b)

Figure 13. Antenna IV: (a) The shape of the antenna optimized to radiate over the frequency band $6.0-8.5 \mathrm{GHz}$ and to filter the frequencies $3.5-6.0 \mathrm{GHz}$ and $8.5-11.0 \mathrm{GHz}$. (b) The antenna reflection coefficient. The operational band is marked by the green dashed lines. 
Figure 14 shows that at lower frequencies, Antenna IV has a directional pattern similar to a dipole antenna [22]. That is, the pattern is approximately omnidirectional in the $x z$ plane and a figure-of-eight in the $y z$ plane. As the frequency increases, the design area becomes electrically larger, and the antenna shows a more directive pattern in the $+z$ direction. Table 4 summarizes the gain characteristics of Antenna IV. Figure 15 shows the current distribution on the antenna. At lower frequencies, the current is confined to the vertical branch. At the higher frequencies, the current is confined around the slot between the two arms. This observation illustrates that the vertical branch is responsible for the antenna radiation, and the slot region contributes to the radiation suppression.

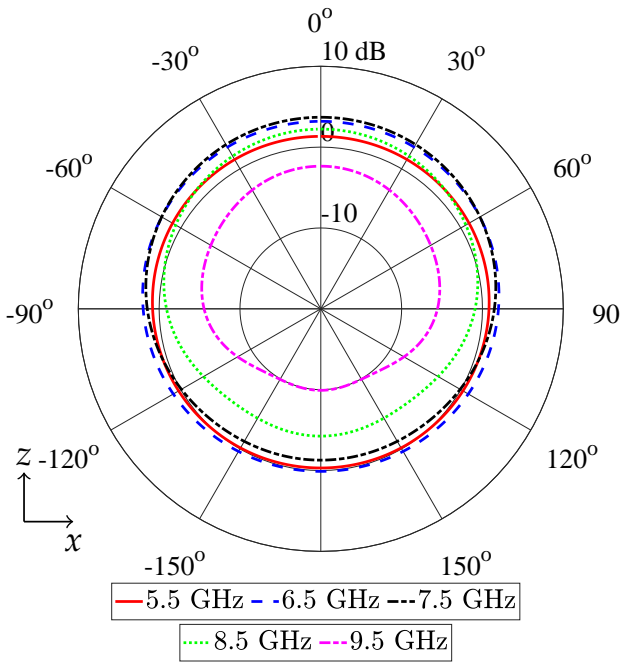

(a)

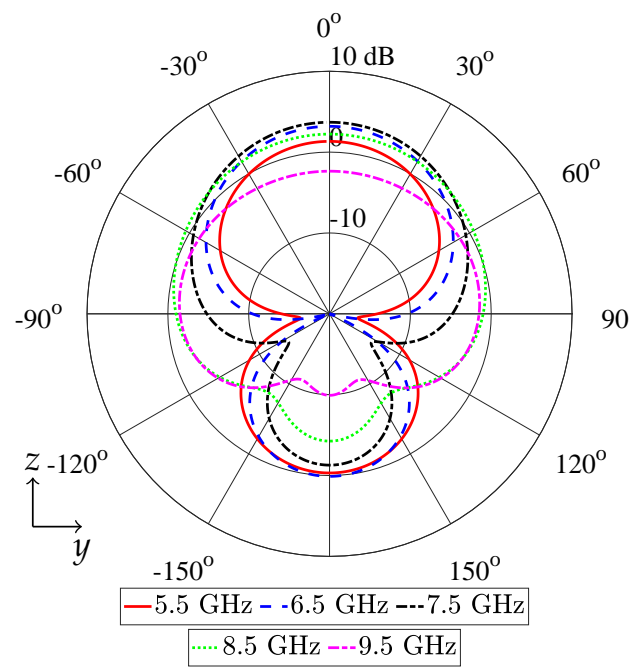

(b)

Figure 14. Antenna IV: (a) Realized gain in the $x z$ plane $(\phi=0)$. (b) Realized gain in the $y z$ plane $(\phi=90)$. The maximum cross-polarization level is less than $52 \mathrm{~dB}$ and $44 \mathrm{~dB}$ for $\phi=0$ and $\phi=90$, respectively.

Table 4. Maximum gain and $3 \mathrm{~dB}$ beamwidths of Antenna IV (Figure 13).

\begin{tabular}{lccccc}
\hline Frequency $(\mathrm{GHz})$ & $\mathbf{5 . 5}$ & $\mathbf{6 . 5}$ & $\mathbf{7 . 5}$ & $\mathbf{8 . 5}$ & $\mathbf{9 . 5}$ \\
\hline Gain $(\mathrm{dB})$ & 1.3 & 3.2 & 3.7 & 2.2 & -2.4 \\
Front-to-back ratio $(\mathrm{dB})$ & 1.6 & 3.1 & 5.0 & 6.5 & 7.6 \\
3 dB beamwidth $(x z$ plane) & $\mathrm{NA}$ & $326^{\circ}$ & $212^{\circ}$ & $180^{\circ}$ & $174^{\circ}$ \\
$3 \mathrm{~dB}$ beamwidth $(y z$ plane $)$ & $90^{\circ}$ & $90^{\circ}$ & $100^{\circ}$ & $174^{\circ}$ & $256^{\circ}$ \\
\hline
\end{tabular}

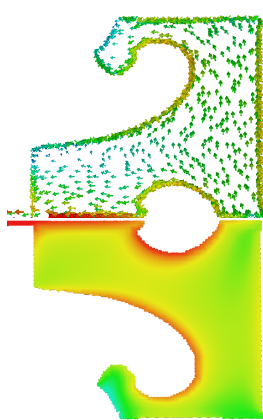

(a) $5.5 \mathrm{GHz}$

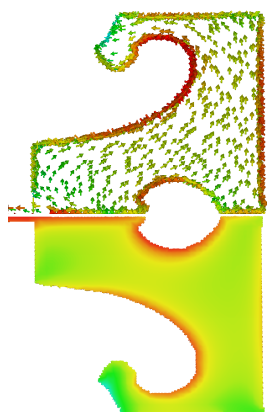

(b) $6.5 \mathrm{GHz}$

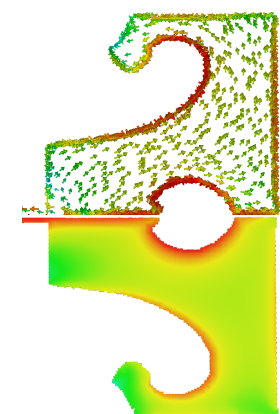

(c) $7.5 \mathrm{GHz}$

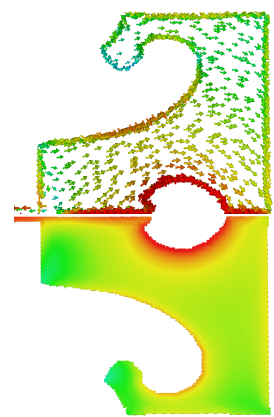

(d) $8.5 \mathrm{GHz}$

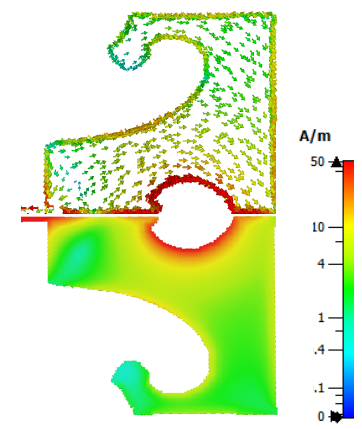

(e) $9.5 \mathrm{GHz}$

Figure 15. Surface current distribution on Antenna IV. 


\section{Discussion}

A comparison between the current work and some previously published filtering antennas is summarized in Table 5. For microstrip antennas, there are expressions to compute the guided wavelength; however, for single-sided planar antennas a definition of the guided wavelength is not obvious. Therefore, we include the physical dimensions and the permittivity of the substrate for each design in Table 5. Two important remarkable differences can be identified between our contribution and the previous work. The first difference lies in the formulation and the methodology employed to realize the filtering antenna. The approach used here can be extended with little effort to other frequency bands. The second difference is that the current work targets wideband filtering antennas, whereas previous contributions focused on narrow band antennas.

Table 5. A comparison between the current work and previously published work.

\begin{tabular}{cccccccc}
\hline Ref. & $\begin{array}{c}\text { Antenna } \\
\text { Type }\end{array}$ & $\begin{array}{c}\text { Center } \\
\text { Frequency }\end{array}$ & $\begin{array}{c}\text { Band- } \\
\text { Width }\end{array}$ & $\begin{array}{c}\text { Gain } \\
\mathbf{( d B )}\end{array}$ & $\begin{array}{c}\text { Design } \\
\text { Concept }\end{array}$ & $\begin{array}{c}\text { Antenna } \\
\text { Volume }\left(\mathbf{m m}^{3}\right)\end{array}$ & $\begin{array}{c}\text { Substrate } \\
\text { Premittivity }\end{array}$ \\
\hline$[5]$ & $\begin{array}{c}\text { Multi-layer } \\
\text { microstrip }\end{array}$ & $3.63 \mathrm{GHz}$ & $9.9 \%$ & 7.5 & $\begin{array}{c}\text { Antenna+ par- } \\
\text { asitic elements }\end{array}$ & $24.4 \times 31.6 \times 3.274$ & 3.55 \\
\hline$[6]$ & $\begin{array}{c}\text { Coaxial-fed } \\
\text { microstrip }\end{array}$ & $5.8 \mathrm{GHz}$ & $5.86 \%$ & 7.28 & $\begin{array}{c}\text { Antenna+ } \\
\text { embedded filter }\end{array}$ & $15.9 \times 29.4 \times 1.575$ & 2.33 \\
\hline$[9]$ & $\begin{array}{c}\text { Coaxial-fed } \\
\text { microstrip }\end{array}$ & $5.24 \mathrm{GHz}$ & $7.0 \%$ & 6.6 & $\begin{array}{c}\text { Antenna+ } \\
\text { embedded slots }\end{array}$ & $13.8 \times 22 \times 1.524$ & 3.55 \\
\hline$[10]$ & $\begin{array}{c}\text { Planar } \\
\text { antenna }\end{array}$ & $2.45 \mathrm{GHz}$ & $14.0 \%$ & 2.41 & $\begin{array}{c}\text { Antenna+ } \\
\text { cascaded filter }\end{array}$ & $30 \times 43 \times 0.6$ & 2.65 \\
\hline $\begin{array}{c}\text { This } \\
\text { work }\end{array}$ & $\begin{array}{c}\text { Planar } \\
\text { antenna }\end{array}$ & $7.25 \mathrm{GHz}$ & $34.0 \%$ & $6 \pm 0.5$ & $\begin{array}{c}\text { Topology opti- } \\
\text { mized antenna }\end{array}$ & $13.5 \times 22.5 \times 0.127$ & 3.0 \\
\hline
\end{tabular}

As was mentioned in Section 3, each pixel in the design domain represents a design variable to be determined by the optimization algorithm. There are 78156 pixels (design variables) in the layouts presented in Figure 3a, Figure 7a, and Figure 10a, while the layout in Figure 13a contains 51200 design pixels. We remark that all the layouts are presented as images with the same aspect ratio as the corresponding optimized antenna. Also, each image has two axes scaled in millimeters. This representation makes the presented layouts easy to reproduce.

\section{Conclusions}

In this paper, the design of planar differential-fed filtering antennas is formulated as a multi-objective topology optimization problem. The vast degrees of freedom offered by the design algorithm make it possible to offer novel compact structures that achieved the design objectives. The optimized antennas have $34 \%$ bandwidth, around $6 \mathrm{~dB}$ uniform in-band gain, and $-8.4 \mathrm{~dB}$ out-of-band gain suppression. Moreover, the antennas have steep roll-off between the out-of-band frequencies and the frequency band of interest at the lower-band edge; however, the roll-off has a moderate slope at the upper-band edge. The proposed antennas have stable broad beamwidths and very low cross-polarization levels over the operational band, which make them favorable candidates for use in applications such as positioning systems. Our numerical experiments show a trade-off between achieving a satisfactory directivity and out-of-band suppression on one hand, and the antenna size on the other.

Author Contributions: Conceptualization, E.H. and D.M.; methodology, E.H., E.W., and M.B.; software, E.H.; validation, D.M. and G.F.; formal analysis, E.H.; resources, E.H., D.M., E.W., G.F. and M.B.; data curation, E.H.; writing—original draft preparation, E.H.; writing—review and editing, E.H., D.M., E.W., G.F. and M.B.; visualization, E.H.

Funding: This work was partially supported by the Swedish strategic research programme eSSENCE. The APC was funded by Electronics. 
Acknowledgments: The computations were performed on resources provided by the Swedish National Infrastructure for Computing (SNIC) at HPC2N center.

Conflicts of Interest: The authors declare no conflict of interest.

\section{Abbreviations}

The following abbreviations are used in this manuscript:

FDTD Finite-Difference Time-Domain method

GCMMA Globally Convergent Method of Moving Asymptotes

GPU Graphics Processing Unit

SMA SubMiniature version A connector

\section{References}

1. Edwards, T.; Steer, M. Foundations for Microstrip Circuit Design; John Wiley \& Sons: Hoboken, NJ, USA, 2016.

2. Pozar, D. Microwave Engineering, 4th ed.; John Wiley \& Sons: Hoboken, NJ, USA, 2012.

3. Röhrl, F.X.; Jakob, J.; Bogner, W.; Hageneder, D.; Zorn, S. Differential wideband interconnects for organic millimeter wave chip packages: An effort to design an all-purpose RF chip package. In Proceedings of the 2016 11th European Microwave Integrated Circuits Conference (EuMIC), London, UK, 3-4 October 2016; pp. 1465-1468. [CrossRef]

4. Scheiner, B.; Mann, S.; Lurz, F.; Michler, F.; Erhardt, S.; Lindner, S.; Weigel, R.; Koelpin, A. Microstrip-to-waveguide transition in planar form using a substrate integrated waveguide. In Proceedings of the 2018 IEEE Radio and Wireless Symposium (RWS), Anaheim, CA, USA, 15-18 January 2018; pp. 18-20. [CrossRef]

5. Wang, W.; Ran, J.; Hu, N.; Xie, W.; Wu, Y.; Kishk, A.A. A novel differential filtering patch antenna with high selectivity. Int. J. RF Microw. Comp. Eng. 2019, 29, e21880. [CrossRef]

6. Liu, Y.; Leung, K.W.; Yang, N. Compact absorptive filtering patch antenna. IEEE Trans. Antennas Propag. 2019, 1-10. [CrossRef]

7. Zhang, B.; Xue, Q. Filtering antenna with high selectivity using multiple coupling paths from source/load to resonators. IEEE Trans. Antennas Propag. 2018, 66, 4320-4325. [CrossRef]

8. Chuang, C.; Chung, S. A compact printed filtering antenna using a ground-intruded coupled line resonator. IEEE Trans. Antennas Propag. 2011, 59, 3630-3637. [CrossRef]

9. Jin, J.Y.; Liao, S.; Xue, Q. Design of filtering-radiating patch antennas with tunable radiation nulls for high selectivity. IEEE Trans. Antennas Propag. 2018, 66, 2125-2130. [CrossRef]

10. Wu, W.; Yin, Y.; Zuo, S.; Zhang, Z.; Xie, J. A new compact filter-antenna for modern wireless communication systems. IEEE Antennas Wireless Propag. Lett. 2011, 10, 1131-1134. [CrossRef]

11. Zhang, X.Y.; Duan, W.; Pan, Y. High-gain filtering patch antenna without extra circuit. IEEE Trans. Antennas Propag. 2015, 63, 5883-5888. [CrossRef]

12. Bendsøe, M.P.; Sigmund, O. Topology Optimization. Theory, Methods, and Applications; Springer: Berlin, Germany, 2003.

13. Deaton, J.D.; Grandhi, R.V. A survey of structural and multidisciplinary continuum topology optimization: Post 2000. Struct. Multidiscip. Optim. 2014, 49, 1-38. [CrossRef]

14. Hassan, E.; Wadbro, E.; Berggren, M. Topology optimization of metallic antennas. IEEE Trans. Antennas Propag. 2014, 62, 2488-2500. [CrossRef]

15. Aage, N.; Egede Johansen, V. Topology optimization of microwave waveguide filters. Int. J. Numer. Meth. Eng. 2017, 112, 283-300. [CrossRef]

16. Wang, J.; Yang, X.S.; Ding, X.; Wang, B.Z. Antenna radiation characteristics optimization by a hybrid topological method. IEEE Trans. Antennas Propag. 2017, 65, 2843-2854. [CrossRef]

17. Hassan, E.; Berggren, M.; Scheiner, B.; Michler, F.; Weigel, R.; Lurz, F. Design of planar microstrip-to-waveguide transitions using topology optimization. In Proceedings of the IEEE Radio and Wireless Symposium (RWS), Orlando, FL, USA, 20-23 January 2019; pp. 1-3. [CrossRef] 
18. Hassan, E.; Wadbro, E.; Hägg, L.; Berggren, M. Topology optimization of compact wideband coaxial-to-waveguide transitions with minimum-size control. Struct. Multidiscip. Optim. 2018, 57, 1765-1777. [CrossRef]

19. Jin, H.; Chin, K.; Che, W.; Chang, C.; Li, H.; Xue, Q. Differential-fed patch antenna arrays with low cross polarization and wide bandwidths. IEEE Antennas Wireless Propag. Lett. 2014, 13, 1069-1072. [CrossRef]

20. De Lera Acedo, E.; Garcia, E.; GonzÁlez-Posadas, V.; Vazquez-Roy, J.L.; Maaskant, R.; Segovia, D. Study and design of a differentially-fed tapered slot antenna array. IEEE Trans. Antennas Propag. 2010, 58, 68-78. [CrossRef]

21. Crampagne, R.; Gratia Khoo. Synthesis of certain transmission lines employed in microwave integrated circuits. IEEE Trans. Microw. Theory Techn. 1977, 25, 440-442. [CrossRef]

22. Balanis, C.A. Antenna Theory: Analysis and Design, 3rd ed.; Wiley-Interscience: Hoboken, NJ, USA, 2005.

23. Hassan, E.; Noreland, D.; Augustine, R.; Wadbro, E.; Berggren, M. Topology Optimization of Planar Antennas for Wideband Near-Field Coupling. IEEE Trans. Antennas Propag. 2015, 63, 4208-4213. [CrossRef]

24. Taflove, A.; Hagness, S. Computational Electrodynamics: The Finite-Difference Time-Domain Method, 3rd ed.; Artech House: Norwood, MA, USA, 2005.

25. Jordan, E.C.; Balmain, K.G. Electromagnetic Waves and Radiating Systems, 2nd ed.; Prentice-Hall: Englewood Cliffs, NJ, USA, 1968.

26. Hassan, E.; Wadbro, E.; Berggren, M. Time-Domain Sensitivity Analysis for Conductivity Distribution in Maxwell's Equations; Tech. Rep. UMINF 15.06; Department of Computing Science, Umeå University: Umeå, Sweden, 2015.

27. Svanberg, K. A class of globally convergent optimization methods based on conservative convex separable approximations. SIAM J. Optim. 2002, 12, 555-573. [CrossRef]

28. Hassan, E.; Wadbro, E.; Berggren, M. Patch and ground plane design of microstrip antennas by material distribution topology optimization. Prog. Electromagn. Res. B 2014, 59, 89-102. [CrossRef]

29. Polo-López, L.; Córcoles, J.; Ruiz-Cruz, J.A. Antenna design by means of the fruit fly optimization algorithm. Electronics 2018, 7, 3. [CrossRef]

30. Smith, J.S.; Baginski, M.E. Thin-wire antenna design using a novel branching scheme and genetic algorithm optimization. IEEE Trans. Antennas Propag. 2019, 67, 2934-2941. [CrossRef]

(C) 2019 by the authors. Licensee MDPI, Basel, Switzerland. This article is an open access article distributed under the terms and conditions of the Creative Commons Attribution (CC BY) license (http:/ / creativecommons.org/licenses/by/4.0/). 